\title{
Unconventional Chiral Amplification in Luminescent Supramolecular Polymers Based on Trisbiphenylamine- tricarboxamides
}

\author{
Yeray Dorca ${ }^{\mathrm{a}} \odot$ \\ Cristina Naranjo ${ }^{\mathrm{a}} \odot$ \\ Goutam Ghosh ${ }^{\mathrm{b}}$ (1) \\ Rafael Gómez ${ }^{\mathfrak{a}}$ (๑) \\ Gustavo Fernández ${ }^{* b}$ (1) \\ Luis Sánchez ${ }^{* a}$ (i) \\ a Departamento de Química Orgánica, Facultad de Ciencias Químicas, Universidad \\ Complutense de Madrid, Ciudad Universitaria, s/n, 28040, Madrid, Spain \\ ${ }^{b}$ Organisch-Chemisches Institut, Westfälische Wilhelms-Universität Münster, \\ Corrensstraße 40, 48149 Münster, Germany \\ gustavo.fernandez@uni-muenster.de; lusamar@ucm.es
}

Received: 17.12 .2019
Accepted after revision: 29.01 .2020
DOI: $10.1055 / \mathrm{s}-0040-1705124$; Art ID: $190026 \mathrm{sc}$
License terms: CCC

(c) 2019. The Author(s). This is an open access article published by Thieme under the terms of the Creative Commons Attribution-NonDerivative-NonCommercial-License, permitting copying and reproduction so long as the original work is given appropriate credit. Contents may not be used for commercial purposes, or adapted, remixed, transformed or built upon. (https://creativecommons.org/licenses/by-nc-nd/4.0/).

Abstract We describe the synthesis of two propeller-shaped, emissive trisbiphenylamines $\mathbf{1}$ and (S)-2. Whilst achiral $\mathbf{1}$ forms supramolecular polymers following a cooperative mechanism, the self-assembly of chiral (S)-2 can be described by an isodesmic mechanism. Despite the isodesmic character of the supramolecular polymerization of (S)-2, an efficient transfer of chirality from the embedded point chirality of the peripheral side chains to the aggregates is demonstrated. The coassembly of $\mathbf{1}$ and (S)- $\mathbf{2}$ in a sergeants-and-soldiers experiment shows a very different dichroic response to that registered for pristine (S)-2, with a copolymerization curve displaying two transitions. Both these transitions coincide with those observed for the pristine achiral and chiral components, thus suggesting a self-sorting effect.

Key words Cooperativity, isodesmic, helical structures, supramolecular polymerization, triarylamines

\section{Introduction}

Triarylamines are organic scaffolds commonly used in organic electronics. ${ }^{1}$ The electron-donating properties of these systems have been exploited to prepare a number of hole-transporting materials. ${ }^{1}$ Importantly, achieving efficient devices from these materials requires the formation of well-organized micro- and nanostructures that limit the presence of defects in the active layer. $^{2} \mathrm{~A}$ general methodology for attaining this organization is the supra-

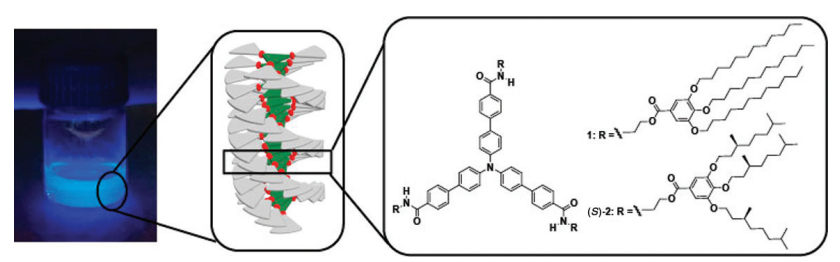

molecular approach that allows the formation of fibrillar structures. ${ }^{3}$ After the pioneering example of Giuseppone and coworkers reporting the conductive properties of columnar stacks of triphenylamines, ${ }^{4}$ a number of selfassembling triarylamines have been described. Interesting$\mathrm{ly}$, the propeller shape of the triarylamine core facilitates the efficient formation of helical structures, as elegantly described by the group of Aida and Miyajima, ${ }^{5}$ or the helix-to-superhelix transition recently described by Zhang and coworkers. ${ }^{6}$

The formation of the aforementioned helical structures relies on the efficient supramolecular polymerization of rationally designed monomeric species that often follow the cooperative mechanism. ${ }^{7}$ This process involves an initial nucleation step followed by a rapid and thermodynamically favored elongation process that yields the final chiral outcome. $^{8}$ However, since very recently, triphenylamines have also been observed to exhibit pathway complexity. ${ }^{9}$ Thus, the cooperative supramolecular polymerization of chiral $\mathrm{N}$-centered triarylamine trisamides was demonstrated to form helical structures of opposite handedness depending on temperature. ${ }^{10}$ Initially, this effect was ascribed to the conformational flexibility exhibited by the triarylamine core that yields off- and on-pathway aggregates. ${ }^{10}$ However, recent investigations on triarylamines have revealed the strong influence of the supramolecular interaction of residual water molecules in the apolar solvent utilized to study the transfer of chirality from the monomeric units to the aggregated states. ${ }^{11}$

To further investigate the supramolecular polymerization of propeller-shaped triarylamines, we have designed two trisbiphenylamines decorated with achiral and chiral peripheral side chains (compounds $\mathbf{1}$ and $(S)-\mathbf{2}$, respectively, in Scheme 1). The presence of the biphenyl moiety in supramolecular polymers has been reported to favor the formation of kinetically and thermodynamically controlled 


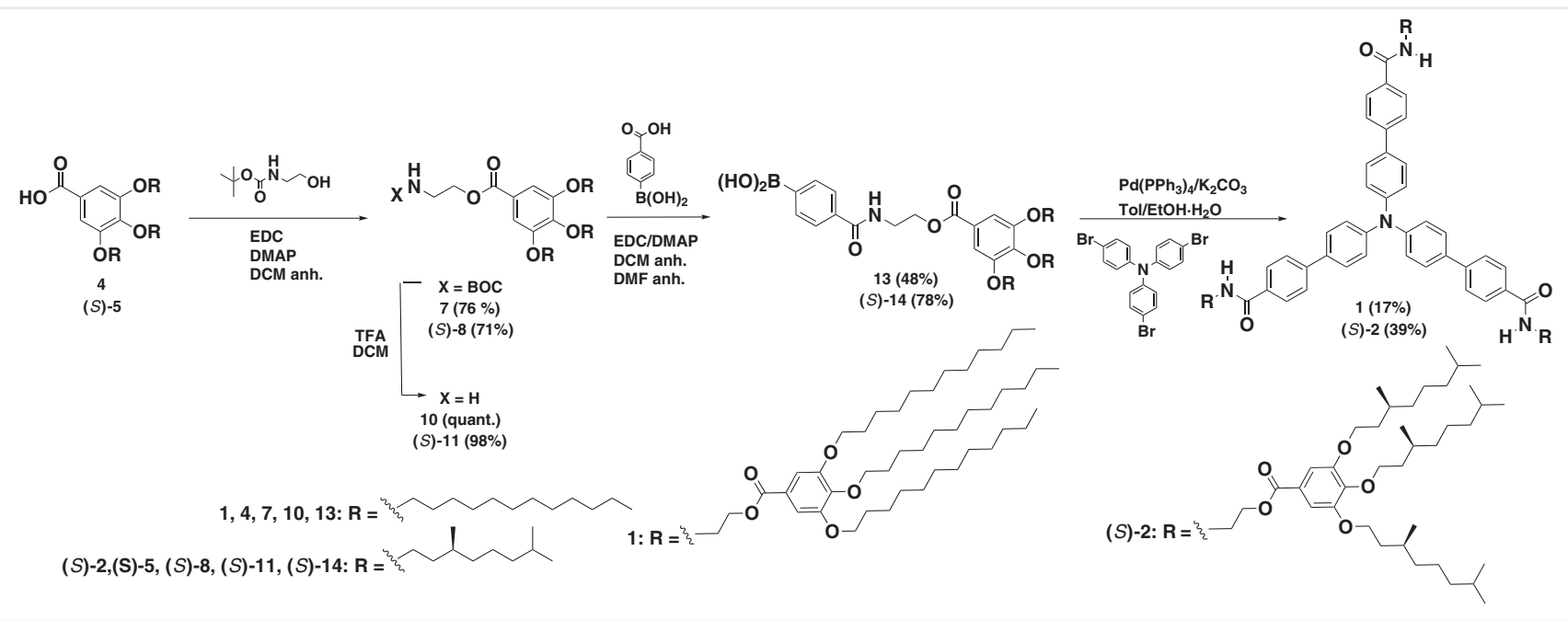

Scheme 1 Synthesis of trisbiphenylamine tricarboxamides $\mathbf{1}$ and (S)-2.

supramolecular polymers. ${ }^{12}$ In this manuscript, we conducted preliminary investigation of the self-assembling features of these two triarylamines by using variable temperature (VT) UV-Vis experiments in methylcyclohexane $(\mathrm{MCH})$ as a solvent. The experimental results show an unexpected influence of the peripheral side chains on the supramolecular polymerization mechanism. In the case of the achiral 1, the supramolecular polymerization occurs in a highly cooperative way. However, chiral (S)-2 exhibits a selfassembling behavior that can be accurately fitted to an isodesmic mechanism defined by a single binding constant. ${ }^{8}$ Unlike the results previously described for referable triphenylamines, the co-assembly of compounds $\mathbf{1}$ and $(S)-2$ in a sergeants-and-soldiers $(\mathrm{SaS})^{13}$ experiment does not result in a typical chiral amplification phenomenon. Instead, a different dichroic response to that registered for pristine (S)-2 is observed. This different dichroic response suggests the potential generation of a hierarchical chiral structure of both components or a kinetic effect, as it has been previously described for referable systems. ${ }^{14}$ Finally, the presence of the biphenyl units in compounds $\mathbf{1}$ and (S)-2 affords highly luminescent samples both in solution and in the solid state. The results presented herein contribute to the expansion of the knowledge on luminescent supramolecular polymers that hold potential applicability in the field of organic electronics.

\section{Results and Discussion}

Trisbiphenylamines $\mathbf{1}$ and $\mathbf{2}$ have been prepared via a multistep protocol with a final Pd-catalyzed Suzuki crosscoupling reaction between commercially available tris(4bromophenyl)amine and the corresponding (4-((2-)(3,4,5trialkoxybenzoyl)oxy)ethyl)-carbamoyl)phenyl)boronic acid. The latter is synthesized in four steps from 3,4,5trialkoxybenzoic acid and N-Boc-protected 2-aminoethan1-ol (Scheme 1). The chemical structures of all the new compounds have been confirmed by NMR and FTIR spectroscopic data, as well as the corresponding mass spectra (see the Supporting Information).

The supramolecular polymerization of compounds $\mathbf{1}$ and (S)-2 has been initially investigated by VT-UV-Vis experiments using $\mathrm{MCH}$ as the solvent and a total concentration $\left(c_{\mathrm{T}}\right)$ of $10 \mu \mathrm{M}$. The UV-Vis spectrum of triarylamine 1 under these experimental conditions at $10^{\circ} \mathrm{C}$ presents two broad bands centered at 264 and $354 \mathrm{~nm}$ and a shoulder at $394 \mathrm{~nm}$ (Figure 1a). Heating this solution to $90{ }^{\circ} \mathrm{C}$ transforms this absorption pattern in an UV-Vis spectrum with two more intense sharper bands centered at 263 and $357 \mathrm{~nm}$ that correspond to the monomeric species (Figure 1a). The hypochromic and the weak hypsochromic shift observed upon cooling the solution of triarylamine 1 are diagnostic of the formation of H-type aggregates. ${ }^{15}$ The stability of the aggregates formed from compound $\mathbf{1}$ has been investigated by deriving the thermodynamic parameters by global fitting of the nonsigmoidal curves, obtained by cooling four solutions of $\mathbf{1}$ from 90 to $10{ }^{\circ} \mathrm{C}$, to the equilibrium (EQ) model described by ten Eikelder and coworkers (Figure 1b). ${ }^{16}$ A complete set of such thermodynamic parameters, namely, the enthalpy of elongation, $\Delta H_{\mathrm{e}}$, the entropy of elongation, $\Delta S$, and the nucleation penalty, $\Delta H_{\mathrm{n}}$, is collected in Table 1 . The high values of $\Delta H_{\mathrm{e}}$, together with the high values of the elongation temperatures $\left(T_{\mathrm{e}}\right)$, that is, the temperature at which the nucleation regime changes to the elongation one, are indicative of the high stability of the supramolecular polymers. These values are higher than others reported for benzenetricarboxamides, ${ }^{17 a}$ $\pi$-conjugated tricarboxamides, ${ }^{13 \mathrm{~b}}$ or boron dipyrromethenes ${ }^{17 \mathrm{~b}}$ and are in the same range as metal complexes. ${ }^{17 \mathrm{c}}$ At 

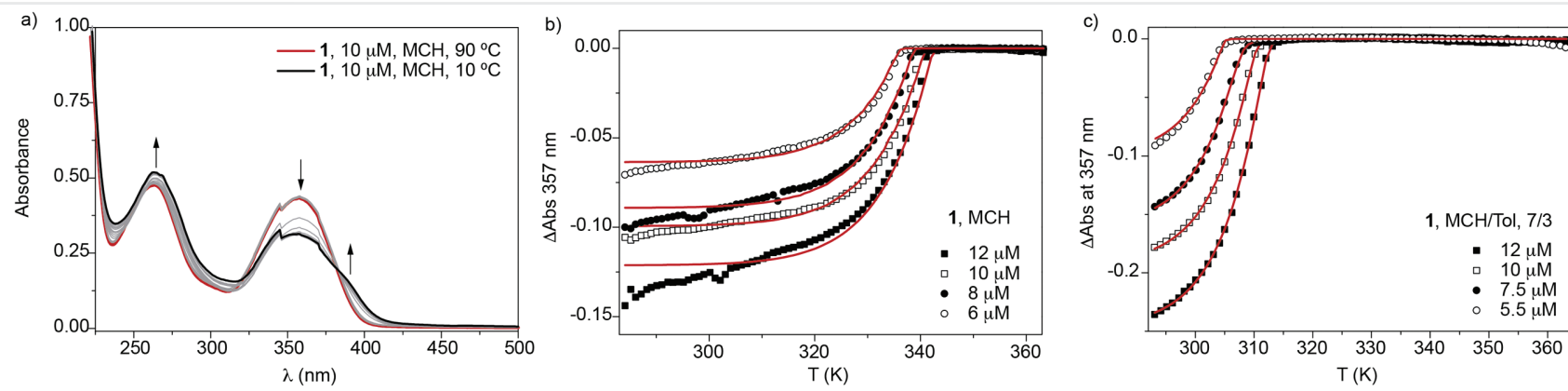

Figure 1 (a) UV-Vis spectra of 1 at different temperatures $\left(\mathrm{MCH}, \mathrm{C}_{\mathrm{T}}=10 \mu \mathrm{M}\right)$. Arrows indicate the absorption changes upon cooling down the solution from 90 to $10^{\circ} \mathrm{C}$. Plot of the variation of the absorbance of $\mathbf{1}$ at $\lambda=357 \mathrm{~nm}$ versus temperature at different concentrations and by using $\mathrm{MCH}$ (b) or a mixture $\mathrm{MCH} / \mathrm{Tol}, 7 / 3$ (c) as the solvent. The red lines in (b) and (c) correspond to the fit to the EQ model.

the same time, the total free energy of the supramolecular polymers of 1 depends on the penalty incorporated by the loss of entropy, which is slightly higher than others reported in the literature, ${ }^{13 \mathrm{~b} 17}$ and the enthalpic cost necessary to achieve the active nucleus (Table 1). The influence of the solvent on the stability of supramolecular polymers is a known effect that has been scarcely evaluated by a comparative thermodynamic study. To evaluate the influence of the solvent on the stability of the supramolecular polymers of $\mathbf{1}$, we have also performed the thermodynamic analysis by using a mixture of $\mathrm{MCH}$ and toluene (Tol) in a 7/3 ratio. This specific solvent mixture was chosen because it enables monitoring the full monomer-to-aggregate transition. While in Tol, and at $c_{\mathrm{T}}=10 \mu \mathrm{M}$, these compounds are molecularly dissolved, in the $\mathrm{MCH} / \mathrm{Tol}(7 / 3)$ mixture, the aggregates are formed at $20^{\circ} \mathrm{C}$ but are readily disassembled by heating the mixture at $90^{\circ} \mathrm{C}$.

Under these conditions, the absorption features of both the aggregates and the monomeric species are identical to those observed in pure $\mathrm{MCH}$. Also, the cooling curves for solutions of $\mathbf{1}$ in $\mathrm{MCH} / \mathrm{Tol}(7 / 3)$ at different concentrations display the same nonsigmoidal shape characteristic of a cooperative supramolecular polymerization (Figures S1

Table 1 Thermodynamic parameters for compounds 1 and (S)-2

\begin{tabular}{llll}
\hline & $\mathbf{1}(\mathrm{MCH})$ & $\mathbf{1}(\mathrm{MCH} / \mathrm{Tol}, 7 / 3)$ & $(\mathrm{S})-\mathbf{2}(\mathrm{UV}, \mathrm{MCH})$ \\
\hline$\Delta H_{\mathrm{e}}[\mathrm{kJ} / \mathrm{mol}]$ & $-104.8 \pm 2$ & $-96.9 \pm 3$ & $-172.5 \pm 7$ \\
$\Delta S[\mathrm{~J} / \mathrm{kmol}]$ & $-212 \pm 5$ & $-216 \pm 10$ & $-446 \pm 23$ \\
$\Delta H_{\mathrm{n}}[\mathrm{kJ} / \mathrm{mol}]^{\mathrm{a}}$ & $-33.5 \pm 10$ & $-24.8 \pm 4$ & $-2.2 \pm 0.5$ \\
$\sigma[-]^{\mathrm{b}}$ & $1.3 \times 10^{-6}$ & $4.4 \times 10^{-5}$ & 0.4 \\
$K_{\mathrm{e}}[\mathrm{L} / \mathrm{mol}]^{\mathrm{b}}$ & $2.6 \times 10^{7}$ & $5.1 \times 10^{5}$ & $8.9 \times 10^{6}$ \\
$K_{\mathrm{n}}[\mathrm{L} / \mathrm{mol}]^{\mathrm{b}}$ & 2.3 & 23 & $3.6 \times 10^{6}$ \\
$\Delta G_{\mathrm{e}}[\mathrm{kJ} / \mathrm{mol}]$ & $-41.7 \pm 6$ & $-32.5 \pm 4$ & $-39.6 \pm 2$
\end{tabular}

aThe nucleation penalty $\Delta H_{\mathrm{n}}$ is negative, which implies that the enthalpy gain is smaller for nucleation compared to elongation.

${ }^{\text {b}}$ The equilibrium constants for elongation and dimerization, $K_{\mathrm{e}}$ and $K_{\mathrm{n}}$, and the cooperativity factor $\sigma\left(=K_{\mathrm{n}} / K_{\mathrm{e}}\right)$ are calculated at $298 \mathrm{~K}$. and 1c). The addition of the "good" solvent Tol results in a decreasing effect on the $T_{\mathrm{e}}$ values and on both enthalpic $\Delta H_{\mathrm{n}}$ and $\Delta H_{\mathrm{e}}$ terms (Table 1 ). However, the entropic cost is not sensibly modified. Consequently, the addition of Tol results in lower, but yet remarkable, values of $K_{\mathrm{e}}$ and the degree of cooperativity $\sigma$ (Table 1 ).

We have also performed a similar analysis for chiral (S)2. As expected, the absorption patterns of the molecular dissolved species of both achiral $\mathbf{1}$ and chiral (S)-2 are identical. However, this is not the case for the aggregated species of (S)-2. For this species, the UV-Vis spectrum in $\mathrm{MCH}$ at $10{ }^{\circ} \mathrm{C}$ and $c_{\mathrm{T}}=10 \mu \mathrm{M}$ shows, in good analogy to $\mathbf{1}$, two broad bands centered at 269 and $345 \mathrm{~nm}$ but no shoulder at $394 \mathrm{~nm}$ (Figure S2). These absorption changes imply, similar to compound $\mathbf{1}$, the formation of $\mathrm{H}$-type aggregates. ${ }^{15}$ Nevertheless, considering that the only difference between triarylamines $\mathbf{1}$ and $(S)-\mathbf{2}$ is the branched nature of the peripheral side chains, the dissimilar absorption pattern could be ascribed to a different rotation angle between the cores in the aggregates of $\mathbf{1}$ and (S)-2 due to the steric hindrance between the side chains. ${ }^{18}$ Interestingly, the cooling curves of (S)-2 present a sigmoidal shape indicative of an isodesmic mechanism (Figure 2). ${ }^{8}$ In fact, the thermodynamic parameters of this chiral triarylamine, derived by fitting these sigmoidal curves to the EQ model, clearly correspond to an isodesmic mechanism in which the $\Delta H_{n}$ value is very low $\left(-2.2 \mathrm{~kJ} \mathrm{~mol}^{-1}\right)$ and the degree of cooperativity $\sigma$ is relatively close to unity (0.4; Table 1$)$.

The presence of stereogenic centers with an (S) absolute configuration at the peripheral side chains in (S)-2 yields helical aggregates, as demonstrated by circular dichroism (CD) studies in MCH (Figure 2c). The presence of bands at $\lambda=233,266,315,354$, and $374 \mathrm{~nm}$ and an isodichroic point at $\lambda=357 \mathrm{~nm}$, coincident with the absorption maximum, is diagnostic of the formation of helical stacks with an $M$-type handedness. ${ }^{7,18,19}$ Therefore, the supramolecular polymerization of (S)-2 is one of the scarce examples in which an efficient transfer of the point chirality, embedded in the 

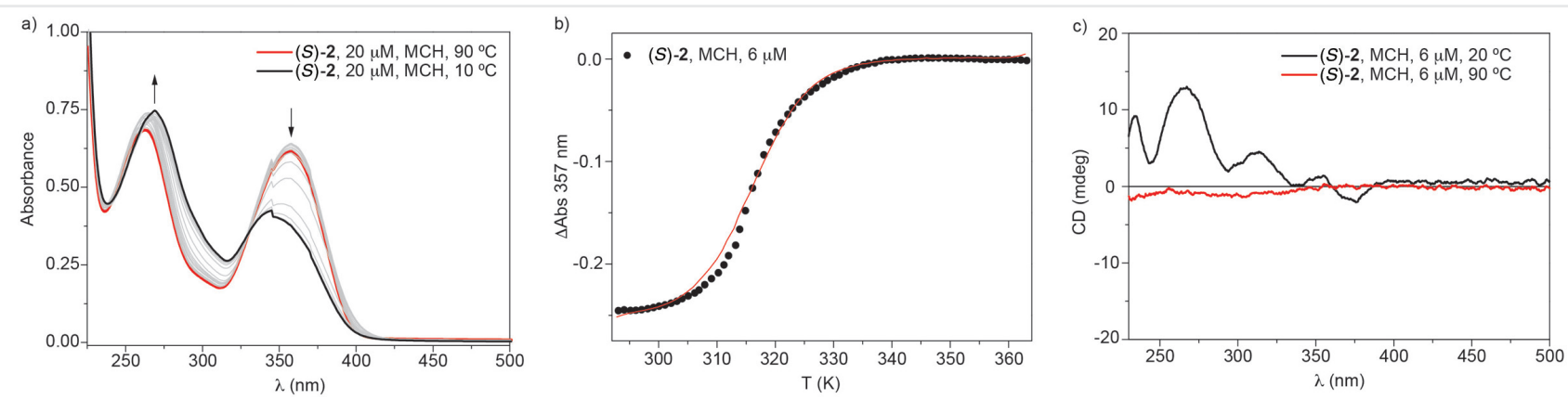

Figure 2 (a) UV-Vis spectra of (S)-2 at different temperatures $\left(\mathrm{MCH}, \mathrm{C}_{\mathrm{T}}=10 \mu \mathrm{M}\right)$. Arrows indicate the absorption changes upon cooling down the solution from 90 to $10^{\circ} \mathrm{C}$. (b) Plot of the sigmoidal variation of the absorbance of 1 at $\lambda=357 \mathrm{~nm}$ versus temperature $\left(\mathrm{MCH}, \mathrm{C}_{\mathrm{T}}=6 \mu \mathrm{M}\right)$. The red line in (b) corresponds to the fit to the EQ model. (c) CD spectra of (S)-2 at different temperatures ( $\left.M C H, c_{T}=10 \mu M\right)$.

peripheral side chains of the self-assembling units, is achieved in an isodesmic-controlled supramolecular polymerization mechanism. ${ }^{20}$ After demonstrating the transfer of chirality experienced by the aggregates of (S)-2, we have performed studies of chiral amplification by carrying out SaS experiments. In these studies, dissimilar amounts of achiral soldier 1, which exhibits no dichroic response (Figure 3), and chiral sergeant (S)-2 are mixed keeping the total concentration constant. Subsequently, the evolution of the $C D$ signal was monitored upon increasing the amount of the chiral sergeant. ${ }^{7,13,18}$ In a typical SaS experiment, obtaining a nonlinear variation of the dichroic response versus the molar fraction of the chiral sergeant implies a chiral amplification phenomenon.

To perform these SaS experiments, we have prepared stock solutions of $\mathbf{1}$ and $(S)-2$ in $\mathrm{MCH}$ at $c_{\mathrm{T}}=10 \mu \mathrm{M}$ and subsequently mixed the corresponding amounts of both the sergeant and soldier. Considering that the supramolecular polymerization mechanism and the $T_{\mathrm{e}}$ values are different for both triarylamines (Table 1 ), the mixture was heated up to $90{ }^{\circ} \mathrm{C}$ and allowed to stand at that temperature for 5 minutes to ensure the complete disassembly of both triarylamines. After this time, the mixture was cooled down to $20{ }^{\circ} \mathrm{C}$ at a rate of $1 \mathrm{~K} / \mathrm{min}$ and the $\mathrm{CD}$ spectra of the mixture were registered for all the ranges of molar fractions in time intervals of 5 minutes. Unexpectedly, mixing both achiral 1 and chiral (S)-2 results in a completely different dichroic pattern to that registered for the pristine sergeant, a phenomenon that has been rarely reported in the literature. $^{21}$ The $C D$ spectra of the mixture display a negative band at $\lambda=258 \mathrm{~nm}$ and two positive bands at $\lambda=335$ and $365 \mathrm{~nm}$ with an isodichroic point at $\lambda=278 \mathrm{~nm}$ (Figures 3 and S5a).

Plotting the variation of the dichroic signal at $\lambda=258 \mathrm{~nm}$ versus the molar fraction of chiral (S)-2 shows a parabolic trend in which this signal increases in intensity until a maximum response is attained for the mixture with a molar fraction of 0.5 of (S)-2. Further increasing the amount of the chiral sergeant decreases the intensity of the $C D$ pattern
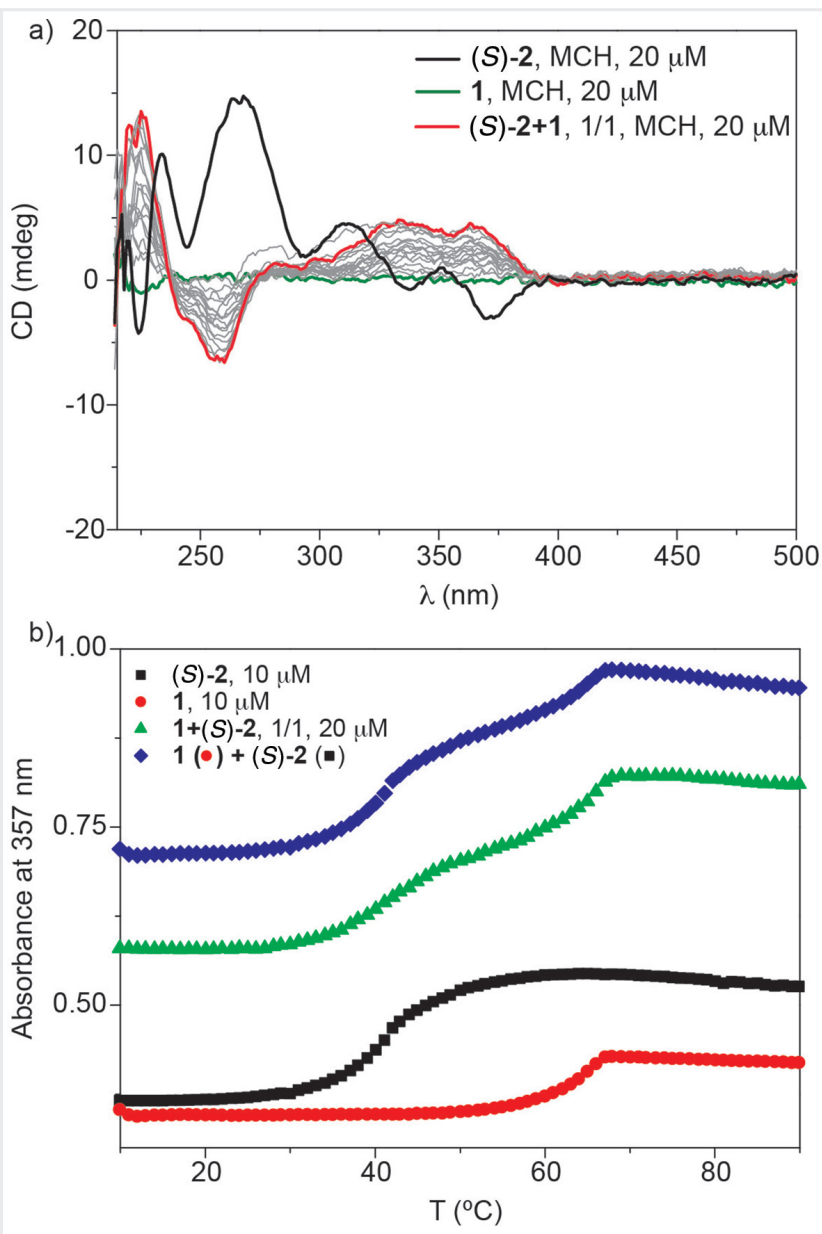

Figure 3 (a) CD spectra obtained for the SaS experiments performed by mixing unequal amounts of enantiomer (S)-2 and $\mathbf{1}\left(c_{T}=10 \mu \mathrm{m} ; \mathrm{MCH}\right.$ as solvent). (b) Cooling curves obtained for compounds $\mathbf{1}$ and (S)-2 at $c_{T}=10 \mu \mathrm{M}$; the mixture $1+(\mathrm{S})-\mathbf{2}(1 / 1)$ at $c_{T}=20 \mu \mathrm{M}$, and the sum of the cooling curves of $\mathbf{1}$ and (S)-2. 
(Figure S4). The CD pattern registered for the mixtures of $\mathbf{1}+(S)-\mathbf{2}$ could be rationalized by considering two different hypotheses: (i) the operation of a kinetic process in which the formation of kinetic traps conditions the dichroic outcome, ${ }^{13}$ or (ii) the formation of new species in which the co-assembly of both triarylamines does not occur by the common intercalation of the aromatic moieties to yield helical columnar stacks. ${ }^{5,22}$

The first hypothesis should involve the time-dependent evolution of the $C D$ spectra of the mixtures due to the previous formation of kinetic traps. These kinetic traps should show a dichroic outcome different to that registered for the thermodynamically controlled supramolecular polymers formed from chiral (S)-2. ${ }^{13}$ Thus, we have registered the $C D$ spectra of the $\mathbf{1}+(S)-\mathbf{2}$ mixtures 24 hours after the preparation of the samples. At this time, no changes are observed in the CD spectra, which suggests a negligible influence of kinetic traps on the helical organization of the mixture (Figure S5b). To validate the second hypothesis, we have registered the absorption cooling curves of the $1 / 1$ mixture of $\mathbf{1}+(S)-\mathbf{2}$ in $\mathrm{MCH}$ at $c_{\mathrm{T}}=20 \mu \mathrm{M}$. The co-assembly of both triarylamines through $\pi$-stacking interactions should provide a new helical species with a similar dichroic pattern to chiral (S)-2 but, at the same time, with a copolymerization cooling curve different from the sum of the curves registered for both separate components. ${ }^{23}$ Figure $3 \mathrm{~b}$ illustrates the copolymerization cooling curve of the $1 / 1$ mixture of $\mathbf{1}+(S)-\mathbf{2}$, the cooling curves of both components separately, and also the sum of the curves of pristine $\mathbf{1}$ and $(S)-\mathbf{2}$ at $c_{\mathrm{T}}=10 \mu \mathrm{M}$. The copolymerization curve displays two transitions that exactly coincide with those observed for the separate components. ${ }^{24}$ Considering that the total concentration of the mixture is $20 \mu \mathrm{M}$, the coincidence of the values of $T_{\mathrm{e}}$ with those registered for pure $\mathbf{1}$ and (S)-2 at $c_{\mathrm{T}}=10 \mu \mathrm{M}$ is a clear indication of the self-sorting of both components in the mixture with no interaction between the aromatic units. However, the dissimilar CD spectra of this mixture in comparison to those registered for pristine chiral (S)-2 is indicative of the potential interaction of the aggregates of $\mathbf{1}$ and (S)-2. These findings require further investigations of the chiral amplification phenomenon of the reported trisbiphenylamines, in particular the role of the peripheral side chains in their supramolecular polymerization.

Finally, and as a proof of principle, we show the strong luminescence exhibited by the reported trisbiphenylamines. The presence of the biphenyl moieties in these compounds results in clear emissive properties both in solution and in the solid state (Figures 4 and S6). As in the case of the UV-Vis experiments, the peripheral side chains also play a relevant role in the final emissive outcome with different photoluminescent features for $\mathbf{1}$ and (S)-2. First, the intensities of both compounds are different, the more

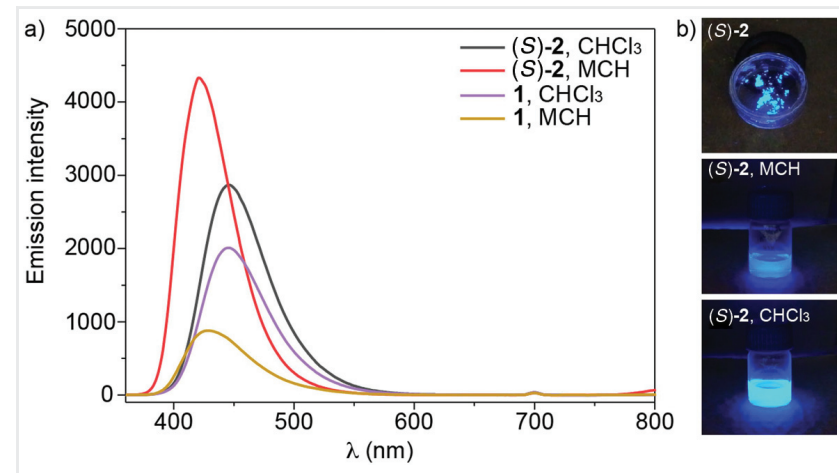

Figure 4 (a) Emission spectra of $\mathbf{1}$ and (S)- $\mathbf{2}$ in different solvents $\left(c_{\mathrm{T}}=10 \mu \mathrm{M}, 298 \mathrm{~K}, \lambda_{\mathrm{exc}}=365 \mathrm{~nm}\right)$; (b) pictures of the luminescent solid and solutions of triarylamine (S)-2 upon irradiation at $365 \mathrm{~nm}$.

intense being that registered for chiral (S)-2. Second, the emission maximum in the aggregated state $(\mathrm{MCH})$ is slightly red-shifted in $(S)-2\left(\lambda_{\max }=430 \mathrm{~nm}\right)$ in comparison to $1\left(\lambda_{\max }=422 \mathrm{~nm}\right)$. Third, and more intriguingly, whilst chiral $(S)-2$ experiences an intensity increase in the aggregated state, the contrary is observed for achiral $\mathbf{1}$ in which the emission intensity is higher in $\mathrm{CHCl}_{3}$ (molecularly dissolved state) than in $\mathrm{MCH}$ (aggregated state; Figure 4a). These findings can be justified by considering the dissimilar rotation angles between the self-assembling units in the aggregate that, in turn, conditions a less efficient $\pi$-stacking. The lack of the shoulder observed in the UV-Vis spectrum of aggregates of chiral 2 (Figure 2a) and the blue-shift observed in the emission spectra in comparison to achiral $\mathbf{1}$ could account for these dissimilar emissive features. ${ }^{17 \mathrm{c}}$ At the same time, the highly emissive aggregates formed from the reported trisbiphenylamines could be indicative of the operation of aggregation-induced enhanced emission (AIE; Figures 4b and S6). ${ }^{25}$ Work is in progress to experimentally quantify the potential operation of an AIE effect in the supramolecular polymers of the reported triarylamines that could yield useful emissive materials.

\section{Conclusions}

In summary, we have described the synthesis of two propeller-shaped, emissive trisbiphenylamines decorated with achiral (1) and chiral ((S)-2) peripheral side chains. The derivation of the thermodynamic parameters demonstrates the unexpected influence of these peripheral side chains on the final supramolecular polymerization mechanism. Thus, achiral 1 self-assembles via a highly cooperative mechanism but chiral (S)-2 forms supramolecular polymers in an isodesmic manner. Despite the isodesmic character of the supramolecular polymerization of (S)-2, an efficient 
transfer of chirality from the embedded point chirality of the peripheral side chains to the aggregates is demonstrated. Finally, the co-assembly of $\mathbf{1}$ and (S)-2 in SaS experiments shows a very different dichroic response to that registered for pristine (S)-2. However, the copolymerization curve displays two transitions coincident with those observed for the pristine achiral and chiral components that suggest the operation of a self-sorting effect yielding a hierarchical chiral structure of both components. Work is currently underway to further investigate the co-assembly of the reported trisbiphenylamines as well as the operation of an efficient AIE process that could render useful emissive materials.

\section{Funding Information}

Financial support by the MINECO of Spain (CTQ201782706-P) and Comunidad de Madrid (P2018/NMT-4389) is acknowledged.

\section{Acknowledgment}

Y.D. and C. N. are thankful to Comunidad de Madrid for their predoctoral fellowships.

\section{Supporting Information}

Supporting information for this article is available online at https://doi.org.

\section{References}

(1) (a) Jiang, X.; Karlsson, K. M.; Gabrielsson, E.; Johansson, E. M. J.; Quintana, M.; Karlsson, M.; Sun, L.; Boschloo, G.; Hagfeldt, A. Adv. Funct. Mater. 2011, 21, 2944. (b) Liu, Q.; Jiang, K.; Wang, L.; Wen, Y.; Wang, J.; Ma, Y.; Song, Y. Appl. Phys. Lett. 2010, 96, 213305. (c) Jeon, N. J.; Lee, J.; Noh, J. H.; Nazeeruddin, M. K.; Grätzel, M.; Seok, S. I. J. Am. Chem. Soc. 2013, 135, 19087.

(2) (a) Hoffmann, S. T.; Jaiser, F.; Hayer, A.; Bässler, H.; Unger, T.; Athanasopoulos, S.; Neher, T.; Köhler, A. J. Am. Chem. Soc. 2013, 135, 1772. (b) Kaiser, A. B. Adv. Mater. 2001, 13, 927.

(3) (a) Dorca, Y.; Greciano, E. E.; Valera, J. S.; Gómez, R.; Sánchez, L. Chem. Eur. J. 2019, 25, 5848. (b) Dorca, Y.; Matern, J.; Fernández, G.; Sánchez, L. Isr. J. Chem. 2019, 59, 869.

(4) Faramarzi, V.; Niess, F.; Moulin, E.; Maaloum, M.; Dayen, J-F.; Beaufrand, J-B.; Zanettini, S.; Doudin, B.; Giuseppone, N. Nat. Chem. 2012, 4, 48.

(5) Kim, T.; Mori, T.; Aida, T.; Miyajima, D. Chem. Sci. 2016, 7, 6689.

(6) (a) Li, F.; Li, X.; Wang, Y.; Zhang, X. Angew. Chem. Int. Ed. 2019, 58, 17994. (b) Osypenko, A.; Moulin, E.; Gavat, O.; Fuks, G.;
Maaloum, M.; Koenis, M. A. J.; Buma, W. J.; Giuseppone, N. Chem. Eur. J 2019, 25, 13008.

(7) Palmans, A. R. A.; Meijer, E. W. Angew. Chem. Int. Ed. 2007, 46, 8948.

(8) De Greef, T. F. A.; Smulders, M. M. J.; Wolffs, M.; Schenning, A. P. H. J.; Sijbesma, R. P.; Meijer, E. W. Chem. Rev. 2009, 109, 5687.

(9) Matern, J.; Dorca, Y.; Sánchez, L.; Fernández, G. Angew. Chem. Int. Ed. 2019, 58, 16730.

(10) Adelizzi, B.; Filot, I. A. W.; Palmans, A. R. A.; Meijer, E. W. Chem. Eur. J 2017, 23, 6103.

(11) Van Zee, N. J.; Adelizzi, B.; Mabesoone, M. F. J.; Meng, X.; Aloi, A.; Zha, R. H.; Lutz, M.; Filot, I. A. W.; Palmans, A. R. A.; Meijer, E. W. Nature 2018, 558, 100.

(12) Aparicio, F.; Nieto-Ortega, B.; Nájera, F.; Ramírez, F. J.; López Navarrete, J. T.; Casado, J.; Sánchez, L. Angew. Chem. Int. Ed. 2014, 53, 1373.

(13) Smulders, M. M. J.; Filot, I. A. W.; Leenders, J. M. A.; van der Schoot, P.; Palmans, A. R. A.; Schenning, A. P. H. J.; Meijer, E. W. J. Am. Chem. Soc. 2010, 132, 611.

(14) (a) Valera, J. S.; Gómez, R.; Sánchez, L. Angew. Chem. Int. Ed. 2019, 58, 510. (b) Hifsudheen, M.; Mishra, R. K.; Vedhanarayanan, B.; Praveen, V. K.; Ajayaghosh, A. Angew. Chem. Int. Ed. 2017, 56, 12634.

(15) (a) Lübtow, M.; Helmers, I.; Stepanenko, V.; Albuquerque, R. Q.; Marder, T. B.; Fernández, G. Chem. Eur. J. 2017, 23, 6198. (b) García, F.; Viruela, P. M.; Matesanz, E.; Ortí, E.; Sánchez, L. Chem. Eur. J. 2011, 17, 7755. (c) Aparicio, F.; García, F.; Sánchez, L. Chem. Eur. J. 2013, 19, 3239.

(16) ten Eikelder, H. M. M.; Markvoort, A. J.; de Greef, T. F. A.; Hilbers, P. A. J. J. Phys. Chem. B 2012, 116, 5291.

(17) (a) García, F.; Korevaar, P. A.; Verlee, A.; Meijer, E. W.; Palmans, A R. A.; Sánchez, L. Chem. Commun. 2013, 49, 8674. (b) Allampally, N. K.; Mayoral, M. J.; Chansai, S.; Lagunas, M. C.; Hardacre, C.; Stepanenko, V.; Albuquerque, R. Q.; Fernández, G. Chem. Eur. J. 2016, 22, 7810. (c) Rödle, A.; Ritschel, B.; Mück-Lichtenfeld, C.; Stepanenko, V.; Fernández, G. Chem. Eur. J. 2016, 22, 15772.

(18) Greciano, E. E.; Calbo, J.; Buendía, J.; Cerdá, J.; Aragó, J.; Ortí, E.; Sánchez, L. J. Am. Chem. Soc. 2019, 141, 7463.

(19) Harada, N.; Nakanishi, K. J. Am. Chem. Soc. 1969, 91, 3989.

(20) (a) Buendía, J.; García, F.; Yélamos, B.; Sánchez, L. Chem. Commun. 2016, 52, 8830. (b) Kulkarni, C.; Korevaar, P. A.; Bejagam, K. K.; Palmans, A. R. A.; Meijer, E. W.; George, S. J. J. Am. Chem. Soc. 2017, 139, 13867. (c) Dehm, V.; Chen, Z.; Baumeister, U.; Prins, P.; Siebbeles, L. D. A.; Würthner, F. Org. Lett. 2007, 9, 1085. (d) Metzroth, T.; Hoffmann, A.; Martín-Rapún, R.; Smulders, M. M. J.; Pieterse, K.; Palmans, A. R. A.; Vekemans, J. A. J. M.; Meijer, E. W.; Spiess, H. W.; Gauss, J. Chem. Sci. 2011, 2, 69. (e) Haino, T.; Tanaka, M.; Fukazawa, Y. Chem Comm. 2008, 468.

(21) Ghosh, G.; Paul, M.; Sakurai, T.; Matsuda, W.; Seki, S.; Ghosh, S. Chem. Eur. J. 2018, 24, 1938.

(22) Adelizzi, B.; Aloi, A.; Markvoort, A.J.; Ten Eikelder, H. M. M.; Voets, I. K.; Palmans, A. R. A.; Meijer, E. W.J.Am. Chem. Soc. 2018, 140, 7168.

(23) (a) Adelizzi, B.; Van Zee, N. J.; de Windt, L. N. J.; Palmans, A. R. A.; Meijer, E. W. J. Am. Chem. Soc. 2018, 140, 6110. (b) Coelho, J. P.; Matern, J.; Albuquerque, R. Q.; Fernández, G. Chem. Eur. J. 2019, 25, 8960.

(24) Aratsu, K.; Yagai, S. ChemPlusChem 2019, 84, 619.

(25) Aparicio, F.; Cherumukkil, S.; Ajayaghosh, A.; Sánchez, L. Langmuir 2016, 32, 284. 